\title{
Novel method of sensitivity analysis improves the prioritization of research in anticipatory life cycle assessment of emerging technologies
}

Ravikumar, D.; Seager, T.P.; Cucurachi, S.; Prado, V.; Mutel, C.L.

\section{Citation}

Ravikumar, D., Seager, T. P., Cucurachi, S., Prado, V., \& Mutel, C. L. (2018). Novel method of sensitivity analysis improves the prioritization of research in anticipatory life cycle assessment of emerging technologies. Environmental Science \& Technology, 52(11), 6534-6543.

doi:10.1021/acs.est.7b04517

Version: $\quad$ Publisher's Version

License: $\quad$ Licensed under Article 25fa Copyright Act/Law (Amendment Taverne)

Downloaded from: https://hdl.handle.net/1887/3217542

Note: To cite this publication please use the final published version (if applicable). 


\title{
Novel Method of Sensitivity Analysis Improves the Prioritization of Research in Anticipatory Life Cycle Assessment of Emerging Technologies
}

\author{
Dwarakanath Ravikumar, ${ }^{* \dagger}{ }^{\dagger}$ Thomas P. Seager, ${ }^{\dagger}$ Stefano Cucurachi, ${ }^{\ddagger}$ Valentina Prado, ${ }^{\ddagger}$, \\ and Christopher Mutel ${ }^{\|(0)}$
}
${ }^{\dagger}$ School of Sustainable Engineering and the Built Environment, Arizona State University 660 S. College Avenue, Tempe, Arizona 85281, United States
${ }^{\ddagger}$ Institute of Environmental Sciences CML, Leiden University, Einsteinweg 2, 2333 CC, Leiden, Netherlands
${ }^{\S}$ EarthShift Global LLC, 37 Route 236, Suite 112, Kittery, Maine 03904, United States
"Laboratory for Energy Systems Analysis, Paul Scherrer Institute, 5232 Villigen PSI, Switzerland

\section{Supporting Information}

\begin{abstract}
It is now common practice in environmental life cycle assessment (LCA) to conduct sensitivity analyses to identify critical parameters and prioritize further research. Typical approaches include variation of input parameters one at a time to determine the corresponding variation in characterized midpoints or normalized and weighted end points. Generally, those input parameters that cause the greatest variations in output criteria are accepted as the most important subjects of further investigation. However, in comparative LCA of emerging technologies, the typical approach to sensitivity analysis may misdirect research and

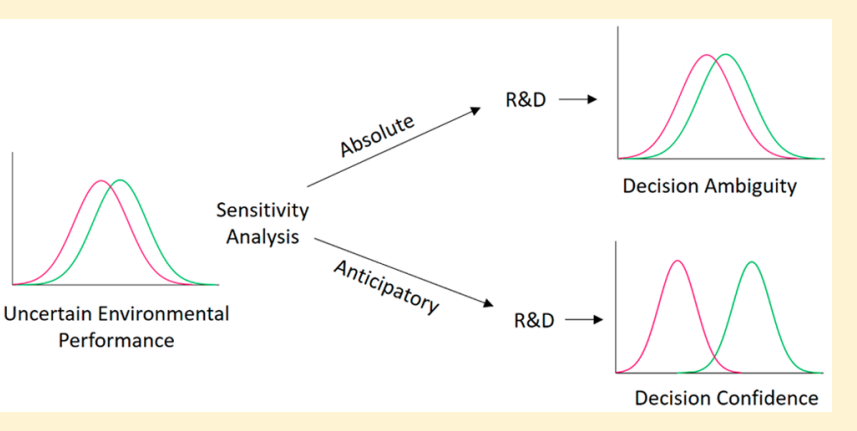
development $(\mathrm{R} \& \mathrm{D})$ toward addressing uncertainties that are inconsequential or counterproductive. This paper presents a novel method of sensitivity analysis for a decision-driven, anticipatory LCA of three emerging photovoltaic (PV) technologies: amorphous-Si (a-Si), CdTe and ribbon-Si. Although traditional approaches identify metal depletion as critical, a hypothetical reduction of uncertainty in metal depletion fails to improve confidence in the environmental comparison. By contrast, the novel approach directs attention toward marine eutrophication, where uncertainty reduction significantly improves decision confidence in the choice between a-Si and CdTe. The implication is that the novel method will result in better recommendations on the choice of the environmentally preferable emerging technology alternative for commercialization.
\end{abstract}

\section{INTRODUCTION}

It is now widely accepted that the proper perspective from which to assess systemic environmental consequences is the product or material life cycle. ${ }^{1}$ Rather than treating environmental issues piece-wise, life cycle assessment (LCA) emerged as an analytical antidote to the environmental ills of manufacturing industries such as metals, chemicals, plastic, automobiles, paper, and fossil fuels. ${ }^{2}$ While LCA also been imagined as a method for steering new technologies toward environmentally preferable outcomes, ${ }^{3}$ the fact is that the dominant practices are inherently retrospective. ${ }^{4}$ As a consequence, emerging technologies such as nanoenabled products present a significant challenge to LCA analysts seeking to mitigate prospective environmental risks. ${ }^{5}$ Key among these challenges is developing informative models for decision support $^{6}$ despite extraordinary data scarcity and uncertainty. ${ }^{7,8}$

Limitations in Traditional Sensitivity-Analysis Methods in a Comparative Assessment of Emerging
Technologies. When faced with high parameter uncertainty, it is difficult to make conclusions regarding the comparative environmental performance of emerging technologies, or identify the critical priorities for further research and development $(\mathrm{R} \& \mathrm{D})$ that might increase decision confidence in the choice an environmentally preferred option from multiple emerging technology alternatives. To address this, LCA analysts frequently rely upon sensitivity analysis to test the influence of uncertain parameters. ${ }^{9,10}$ Traditional approaches ${ }^{11}$ and recent methodological improvements to sensitivity analysis in $\mathrm{LCA}^{12-15}$ are primarily concerned with parameters affecting performance of a single alternative (hereafter, absolute assessment $)^{16,17}$ as opposed to parameters affecting comparison

Received: September 1, 2017

Revised: April 14, 2018

Accepted: May 7, 2018

Published: May 7, 2018 
of multiple alternatives. ${ }^{18}$ Traditional approaches offer advantages when the overall goal is to improve the environmental performance of a specific technology by identifying and addressing hotspots. For example, the traditional approach to sensitivity analysis is well suited to inform $\mathrm{R} \& \mathrm{D}$ programs or industrial manufacturers seeking to identify and address hotspots and improve the environmental performance of a specific technology.

However, traditional practices, when applied in a comparative assessment of technologies, identify uncertainties that may be irrelevant in specific decision contexts, where the priority should be identifying those uncertainties that are most influential to the performance difference between alternatives. ${ }^{18,19}$ For instance, in a comparative LCA where A and B represent the alternatives, fuel use may be the most influential parameter in environmental performance of A. However, when taking into account the relative performance with $\mathrm{B}$, water consumption may be the most influential in making $\mathrm{A}$ and $\mathrm{B}$ distinguishable. Absolute sensitivity analysis informs individual improvements, while comparative sensitivity analysis informs the issues that have the most influence in improving the confidence in the comparison between $\mathrm{A}$ and $\mathrm{B}$. With the exception of a recent illustration, ${ }^{15}$ implementation of sensitivity analysis in LCA literature refers to absolute measures of environmental risk or impact and thus remain ill-suited to inform technology selection in a comparative assessment. ${ }^{20,21}$

An Anticipatory, Decision-Driven Sensitivity-Analysis for Emerging Technologies. Decision-driven approaches in LCA reduces onerous data requirements. ${ }^{20,22}$ When integrated with the novel anticipatory-LCA framework for emerging technologies, the decision-driven approach identifies the most promising option from competing alternatives in a specificenvironmental context and can prioritize further R\&D efforts to inform the selection of the environmentally preferable emerging technology alternative for commercialization. ${ }^{4}$ In addition, the anticipatory, decision-driven approach (hereafter anticipatory approach) avoids external normalization where characterized inventory midpoints are typically divided by reference values applicable to a chosen geographic region. ${ }^{25}$ For example, if the climate impact of manufacturing a product is $1000 \mathrm{~kg} \mathrm{CO}$-eq and the reference value for climate change for the world is $5.76 \times 10^{13}$, ${ }^{24}$ the externally normalized climate change score is $2.39 \times 10^{-11}$. External normalization is avoided because it can potentially mask key environmental trade-offs that impact the choice of preferred alternative. ${ }^{26}$ The anticipatory approach mandates internal normalization ${ }^{23}$ to identify the salient environmental trade-offs that are most sensitive to stakeholder preferences, such as has been implemented in stochastic multiattribute analysis (SMAA) approaches. $^{24}$ Internal normalization benchmarks a technology's environmental performance in relation to the competing alternatives performance through outranking methods, which compare the alternatives on a pairwise basis and normalize the environmental score of the alternatives on a scale between 0 and 1 (the outranking score). The outranking is based on the indifference and preference threshold ${ }^{19}$ (Figure 1). For example, if the difference between the characterized environmental score in an impact category of alternative $\mathrm{X}$ and $\mathrm{Y}$ is greater than the preference threshold $\mathrm{p}$, then $\mathrm{X}$ is strongly preferred over Y. Therefore, the characterized environmental score of $\mathrm{X}$ is normalized to 1 . Similarly, if the difference between the characterized environmental score of alternative $\mathrm{X}$

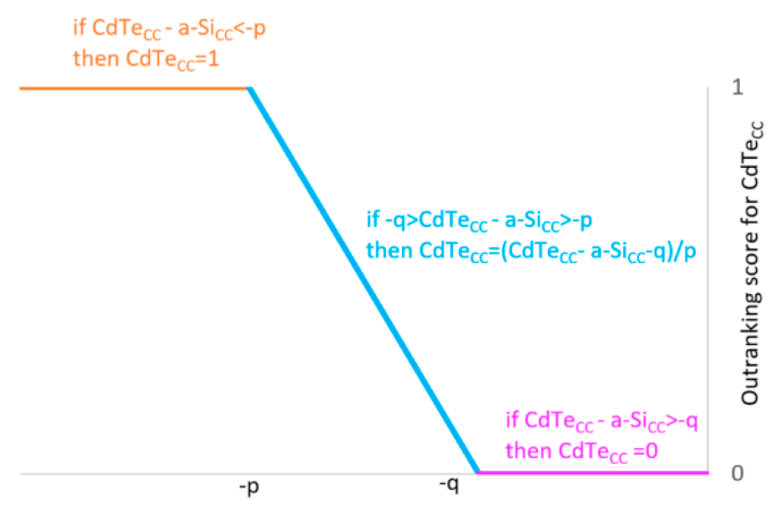

Difference in environmental impact

Figure 1. Preference function (PF) to calculate the outranking score for CdTe in the climate change impact category. $\mathrm{p}$ and $\mathrm{q}$ are the preference and the indifference thresholds, respectively.

and $\mathrm{Y}$ is less than the indifference threshold $\mathrm{q}$, then the characterized inventory midpoint of $\mathrm{X}$ is normalized to 0 .

This work presents a new sensitivity analysis method in LCA to support an anticipatory approach to improve the prioritization of $\mathrm{R} \& \mathrm{D}$ and better inform decisions on technology selection for emerging technologies. To contrast existing approaches that emphasize absolute assessment with the anticipatory approach necessary to identify environmentally promising alternatives at early stages of technology development, we apply the moment independent sensitivity analysis method $^{28-30}$ (Figure 2) to compare three emerging PV technologies. We chose the moment independent sensitivity analysis method as it accounts for higher order interactions, provides quantitative measures of uncertainty contributions from the parameters, and is applicable in scenarios when the input parameters are correlated and the input and outputs are nonlinearly and nonmonotonically related. ${ }^{14}$ Moreover, the recent growth in software and hardware capabilities can meet the high computational resource requirements that previously prevented the widespread adoption of moment independent methods.

In both the assessments, we include weights, sampled from a uniform distribution, to quantify the stakeholder sensitivity to three environmental impact categories-climate change, marine eutrophication and metal depletion. In the absolute assessment, the environmental performance of the three PV technologies (Figure 3 ) is determined by calculating a weighted score (eq 1) after weighting and externally normalizing values sampled from the characterized inventory distribution (Table 1). Therefore, in the absolute assessment, the uncertainty in the weighted score (the output parameter) of each PV technology is dependent on six parameters: the uncertainty in the three weights for the impact categories and the three impact category scores. In the anticipatory approach, the relative rank of the three PV technologies (Figure 3 ) is determined by applying the SMAA framework (eqs 2-7). SMAA ranks the alternatives by weighting and internally normalizing the values obtained from a Monte Carlo sampling of the characterized inventory distribution (Table 1). ${ }^{27}$ An overlap in the highest rank represents the uncertainty in the choice of the environmentally preferred technology alternative. In the anticipatory assessment, the uncertainty in the relative rank of a PV technology (the output parameter) is dependent on the uncertainty in 12 parameters, the three weights for the impact categories and the 
Step 1: Generate 500 samples of the 3 lognormally distributed environmental impact category scores (Table 1) for the PV technology and the 3 uniformly distributed weights in a 500x6 matrix $\left(\mathrm{IP}_{\mathrm{a}}\right)$

$$
\downarrow
$$

Step 2: Generate 500 samples of the 3 lognormally distributed environmental impact category scores (Table 1 ) for the PV technology and the 3 uniformly distributed weights in a 500x6 matrix $\left(\mathrm{IP}_{\mathrm{b}}\right)$

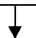

Step 3: Generate a 500x1 matrix $\left(Y_{b}\right)$ by calculating the weighted score (weighted score) for each of the 500 rows in $\mathrm{IP}_{\mathrm{b}}$ using equation 1 .

Step 4: Generate a 500x6 matrix $\left(\mathrm{IP}_{\mathrm{c}}\right)$ by replacing all the elements of the ' $\mathrm{j}$ 'th column in $\mathrm{IP}_{\mathrm{b}}$ with the

element from the ' $i$ 'th row and ' $j$ 'th column from $\operatorname{IP}_{a}(1<=i<=500,1<=j<=6)$. The remaining 5 columns in $\mathrm{IP}_{\mathrm{c}}$ are identical to $\mathrm{IP}_{\mathrm{b}}$.

500 rows in $\mathrm{IP}_{\mathrm{c}}$ using equation 1.

Sten 6: Apply a kernel density estimator and determine the probability density function $\mathrm{PDF}_{\mathrm{Yb}}$ and $\mathrm{PDF}_{\mathrm{Yc}}$ from $\mathrm{Y}_{\mathrm{b}}$ and $\mathrm{Y}_{\mathrm{c}}$, respectively.

\section{$\downarrow$}

Step 7: Determine $S_{j}$ for the $\mathrm{j}^{\text {th }}$ parameter (from the equation given below, $N=500$ ). Calculate $S_{j}$ for each of the 6 input parameters for 500 times by incrementing ' $i$ ' and ' $j$ ' in step 4

$$
---1
$$

$$
\mathrm{S}_{\mathrm{j}}=\frac{1}{\mathrm{~N}} \sum_{\mathrm{m}-1}^{500}\left|\frac{\mathrm{PDF}_{\mathrm{Yz}_{-} \mathrm{m}}}{\mathrm{PDF}_{\mathrm{Y}_{-} \mathrm{m}}}-1\right|
$$

Step 8: Determine $\delta$ for the $\mathrm{j}^{\text {th }}$ parameter

$$
\delta_{\mathrm{j}}=\frac{1}{2 \mathrm{~N}} \sum_{\mathrm{m}=1}^{500} \mathrm{~S}_{\mathrm{j}_{-} \mathrm{m}}
$$

Step 9: Determine $\delta 100$ times by repeating steps 3 to 8

Figure 2. Calculation of moment independent sensitivity analysis index $(\delta)$ to identify the significant uncertainties affecting the weighted score of a PV technology.

Absolute assessment

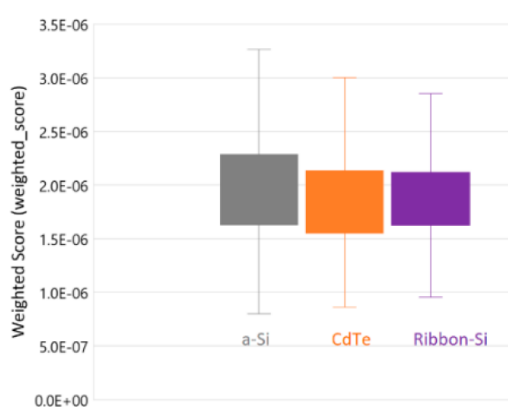

\section{Anticipatory assessment}

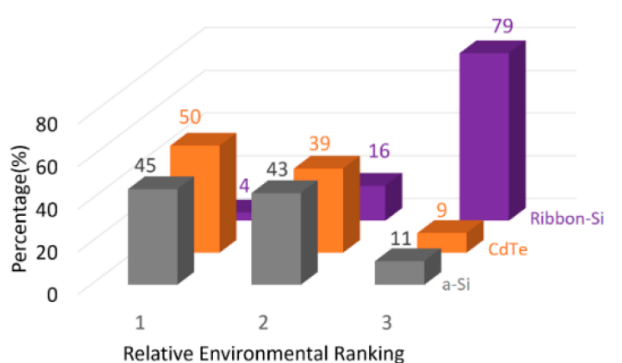

Figure 3. Weighted scores of the three PV technologies in the absolute assessment (left) and the relative rankings in the anticipatory assessment (right). The upper and lower end of the whiskers (left) represent the maximum and minimum value of the weighted_score and the upper and lower end of the box represent the upper and lower quartiles of the weighted_score, respectively. For the anticipatory assessment (right), the $y$-axis depicts the likelihood (out of a 10000 runs) that an alternative was ranked first (most preferred), second or third based on the relative environmental score

\begin{tabular}{|c|c|c|c|c|c|c|}
\hline & \multicolumn{2}{|c|}{$\mathrm{a}-\mathrm{Si}$} & \multicolumn{2}{|c|}{$\mathrm{CdTe}$} & \multicolumn{2}{|c|}{ ribbon-Si } \\
\hline & mean & standard dev & mean & standard dev & mean & standard dev \\
\hline marine eutrophication ( $\mathrm{kg} \mathrm{N}$-eq, weight $=0.65$ to 0.75$)$ & $5.60 \times 10^{-06}$ & $1.50 \times 10^{-06}$ & $6.20 \times 10^{-06}$ & $1.60 \times 10^{-06}$ & $8.80 \times 10^{-06}$ & $2.10 \times 10^{-06}$ \\
\hline climate change $(\mathrm{kg} \mathrm{CO}$ eq, weight $=0.25$ to 0.35$)$ & $1.60 \times 10^{-02}$ & $4.10 \times 10^{-03}$ & $1.30 \times 10^{-02}$ & $2.50 \times 10^{-03}$ & $1.72 \times 10^{-02}$ & $3.60 \times 10^{-03}$ \\
\hline metal depletion ( $\mathrm{kg} \mathrm{Fe}$ eq, weight $=0.05$ to 0.15 ) & $9.00 \times 10^{-03}$ & $2.50 \times 10^{-03}$ & $8.50 \times 10^{-03}$ & $2.10 \times 10^{-03}$ & $6.90 \times 10^{-03}$ & $1.90 \times 10^{-03}$ \\
\hline
\end{tabular}
(eq 2). The $x$-axis represents the rank.

Table 1. Mean and Standard Deviation of the Lognormally Distributed Characterization Scores (Using the ReCiPe Impact Assessment Method) for Generating $1 \mathrm{MJ}$ of Electricity from Three Emerging PV Technologies ${ }^{a}$

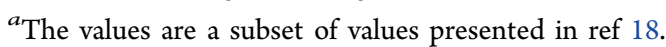




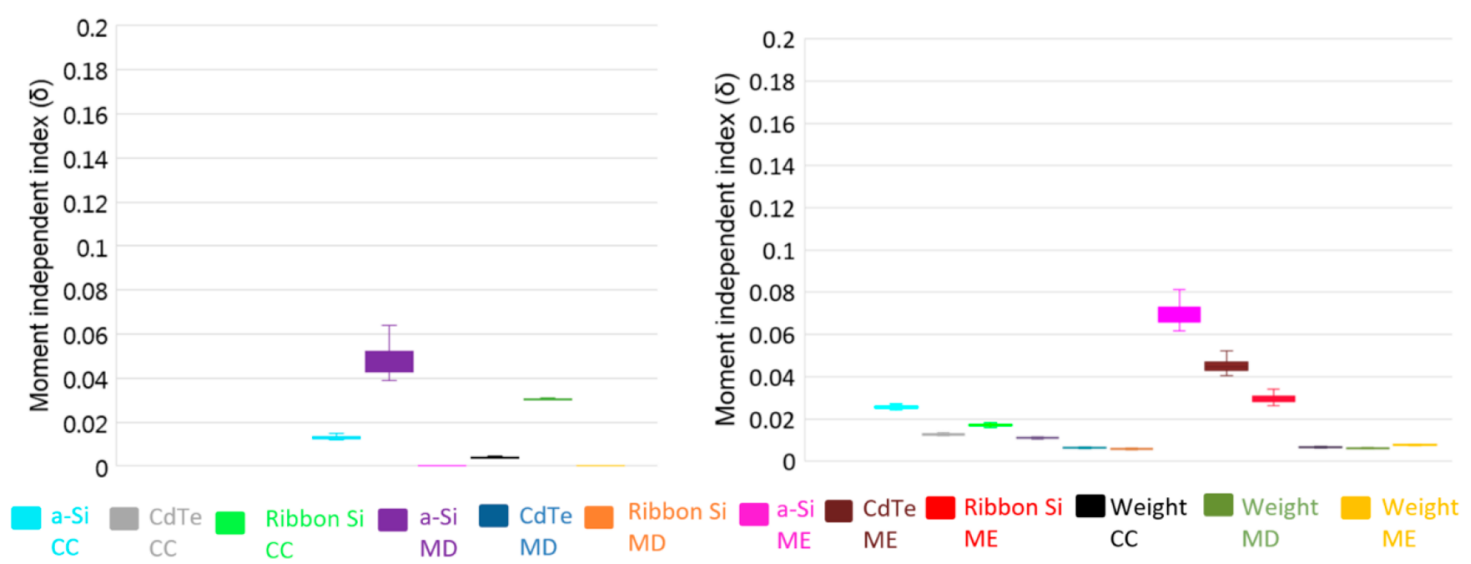

Figure 4. Moment independent index $(\delta)$ values identifying significant uncertainties for the a-Si in the absolute (left) and the anticipatory assessment (right). Uncertainty in the parameters with the highest value of $\delta$ in the figure in the left and right contribute the most to the overall uncertainty in the weighted score ("weighted_score" in eq 1) and the relative score ("rel_score" in eq 2), respectively. CC, climate change; MD, metal depletion; ME- marine eutrophication.

a-Si : Baseline

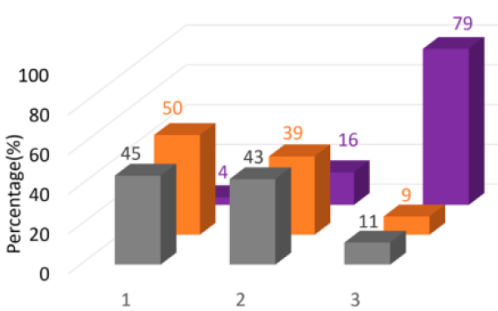

a-Si : Reduced MD mean and S.D.

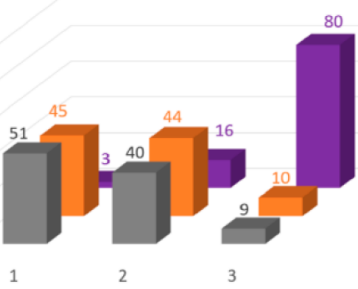

a-Si : Reduced ME mean and S.D.

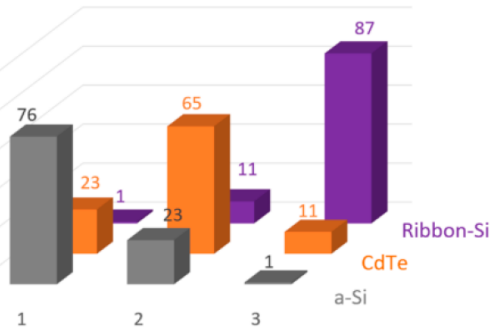

Figure 5. Relative environmental rankings for the three PV technologies in the baseline scenario (left), and when R\&D decreases the critical uncertainty of metal depletion (center) and marine eutrophication (right) for a-Si. The mean is decreased by one standard deviation and the standard deviation is decreased by $50 \%$ from baseline values (Table 1 ).

three impact category scores of each of the three PV alternatives.

To identify critical uncertainties in the absolute and the anticipatory assessment, we apply the moment independent sensitivity analysis to determine the delta $(\delta)$ index values (Figure 2) for each of the input parameters that influence the weighted score and relative ranks. The uncertainty in the input parameters with the greatest $\delta$ value is the most significant (Figure 4). To simulate and contrast outcomes from R\&D efforts informed by the sensitivity analysis in the absolute and the anticipatory assessment, we create two scenarios corresponding to the absolute and the anticipatory assessment. In the absolute and the anticipatory scenario, we decrease the uncertainty in the critical parameters identified by the sensitivity analysis in the absolute and anticipatory assessment, respectively. Based on the decreased uncertainty, the environmental rankings are calculated in both the scenarios and compared with the baseline ranking (Figure 5). The $\mathrm{R} \& \mathrm{D}$ strategy corresponding to the scenario with a lower overlap in the alternatives obtaining the highest environmental rank (compared to the baseline scenario) is better suited for improving the decision confidence in technology selection.

\section{MATERIALS AND METHODS}

The PV industry is making rapid technological improvements as a result of private and public $\mathrm{R} \& \mathrm{D}$ efforts that have improved thermodynamic efficiencies and reduced costs. ${ }^{31-33}$ Nonetheless, PV is far from a technological homogeneous industry.
There is a broad array of commercial, pilot, and research scale chemistries and technologies, each competing for both market share and new investments. Monocrystalline silicon (mono-Si) and multicrystalline silicon (multi-Si) account for around 95\% of all PV modules sold, while cadmium telluride ( $\mathrm{CdTe}$ ) accounts less than $5 \%$, and all other technologies like ribbon-Si, amorphous silicon (a-Si) account for the remainder. ${ }^{34} \mathrm{We}$ choose $\mathrm{CdTe}$, a-Si and Ribbon-Si as a case study for emerging technologies as they are minority technologies and smaller in scale than the market dominant crystalline silicon technologies; proprietary to a single manufacturer (First Solar is the largest U.S. PV manufacturer, but the sole provider of CdTe modules); and have data scarcity and significant uncertainties in material and energy inventory data, especially considering the rapid evolution of technology and manufacturing processes at the leading edge of research.

We evaluate a-Si, CdTe, and ribbon-Si as there is a significant environmental and climate benefit in increasing the manufacturing and deployment of alternative PV technologies which have a lower greenhouse gas (GHG) manufacturing emissions than the market dominant crystalline silicon PV technologies. ${ }^{35,36}$ However, while being less climate intensive, thin film PV technologies such as CdTe, a-Si, and Ribbon-Si may have high burdens in other impact categories such as metal depletion. ${ }^{18}$ To explore the trade-offs, we evaluate the three emerging PV technologies in the decision-context of identifying an alternative offering the lowest climate change $\left(\mathrm{kg} \mathrm{CO}_{2} \mathrm{eq}\right)$, metal depletion ( $\mathrm{kg} \mathrm{Fe} \mathrm{eq)} \mathrm{and} \mathrm{marine} \mathrm{eutrophication} \mathrm{(} \mathrm{kg} \mathrm{N}$ - 
eq) impact for a functional unit of $1 \mathrm{MJ}$ of electricity. The lifecycle inventory (LCI) data used to determine the environmental impacts for generating electricity from $\mathrm{CdTe}$ includes raw material extraction, panel and auxiliary material required to manufacture the CdTe module. ${ }^{18}$ For the silicon alternatives, the LCI data includes quartz reduction, production of solar grade silicon and wafers, and laminate production. ${ }^{18}$ In addition, LCI data for the three PV alternatives includes transportation, materials required for installation and operation of balance of system components (inverters), cleaning, and wiring. ${ }^{18}$ We select only three impact categories to simplify calculations and base the technology choice on the environmental benefit of transitioning away from climate-intensive sources of electricity, reducing the eutrophication impact for PV installations, limiting the feedstock of earth-limited metals used for manufacturing PV, and best illustrate the utility of the novel sensitivity analysis method. ${ }^{37-41}$ The lognormally distributed environmental scores in the three impact categories are obtained from ref 18 which determined the scores by applying the ReCiPe midpoint (Heirarchist) impact assessment method $^{42}$ to $1 \mathrm{MJ}$ of electricity generated from the three PV technologies. The mean $\left(\mu_{\mathrm{N}}\right)$ and the standard distribution $\left(\sigma_{\mathrm{N}}\right)$ of the lognormally distributed environmental scores for the three PV technologies, which are used in the absolute and anticipatory assessment of the PV technologies, are presented in Table 1.

Absolute Assessment of Photovoltaic Technologies. In the absolute assessment, the unitless weighted score (weighted_score) of the three PV technologies is calculated by the weighted sum of the normalized scores in the climate change (CC), metal depletion (MD) and the marine eutrophication (ME) impact categories ${ }^{23,43}$

$$
\text { weighted_score }=\sum_{i=\mathrm{CC}, \mathrm{MD}, \mathrm{ME}} \text { weight }_{\mathrm{i}} \times \text { norm_factor }_{i} \times \text { charac_score }_{i}
$$

where, weight $t_{i}$ norm_fact ${ }_{i}$, charac_score ${ }_{i}$ is the weight, normalization factor, and characterized score in impact category " $i$ ", respectively. The weights for marine eutrophication, climate change, and metal depletion impact categories are assumed to be uniformly distributed between $0.65-0.75,0.25-0.35$, and $0.05-0.15$, respectively. We assume that the weights are uniformly distributed, as there is no standard practice for assigning weights in an LCA. ${ }^{44}$ The choice of the weights reflect a higher emphasis on marine eutrophication and climate change. A lower emphasis is placed on metal depletion as metal feedstock concerns can be addressed by recycling spent PV modules. ${ }^{17,40}$ The uniform distribution is preferred over point values for weights to account for the uncertainty in the stakeholder values. The sum of the weights for the three impact categories is constrained to one. We calculated 10000 values for weighted_score for the three PV technologies by stochastically sampling 10000 values for the impact scores and the weights based on the log-normal distribution properties in Table 1 and, the uniform distributions, respectively. The normalization factors for Europe in the marine eutrophication, climate change, and metal depletion impact categories are $0.0988(\mathrm{~kg} \mathrm{~N}-\mathrm{eq})^{-1}, 0.0000892\left(\mathrm{~kg} \mathrm{CO}_{2} \mathrm{eq}\right)^{-1}$, and $0.0014(\mathrm{~kg}$ $\mathrm{Fe}$ eq $)^{-1}$, respectively. ${ }^{42} \mathrm{We}$ assume point values for the normalization factors as this is the standard practice. ${ }^{42,45}$

Anticipatory Assessment of Photovoltaic Technologies. For the anticipatory assessment, we use outranking methods ${ }^{27,46}$ to rank the three PV technologies based on the relative difference in the environmental scores in marine eutrophication, climate change, and metal depletion impact categories. The relative score (rel_score), ranging between the environmental least preferable $(-1)$ and environmental most preferable $(+1)$, represents the environmental performance of a PV technology relative to the two other alternatives The calculation of the relative score for CdTe is shown in eq 2 and the same is applicable to a-Si and Ribbon-Si

$$
\begin{aligned}
& \text { rel_score }_{\mathrm{CdTe}}=\left[\theta_{(\mathrm{CdTe}, \mathrm{a}-\mathrm{Si})}-\theta_{(\mathrm{a}-\mathrm{Si}, \mathrm{CdTe})}\right] \\
& +\left[\theta_{(\mathrm{CdTe}, \mathrm{Ribbon}-\mathrm{Si})}-\theta_{(\mathrm{Ribbon}-\mathrm{Si}, \mathrm{CdTe})}\right]
\end{aligned}
$$

where $\theta_{(\mathrm{CdTe}, \mathrm{a}-\mathrm{Si})}$ and $\theta_{(\mathrm{CdTe}, \mathrm{Ribbon}-\mathrm{Si})}$ represent the total positive flow of $\mathrm{CdTe}$ with respect to a-Si and Ribbon-Si. The total positive flow is a measure of $\mathrm{CdTe}$ being environmentally preferred over a-Si and Ribbon-Si. Similarly, $\theta_{(\mathrm{a}-\mathrm{Si}, \mathrm{CdTe})}$ and $\theta_{(\mathrm{Ribbon}-\mathrm{Si}, \mathrm{CdTe})}$ represent the negative flows of $\mathrm{CdTe}$ and is a measure of the a-Si and Ribbon-Si being environmentally preferred over CdTe.

The positive flow (e.g., for CdTe over a-Si) is calculated in eq

$$
\begin{aligned}
\theta_{(\mathrm{CdTe}, \mathrm{a}-\mathrm{Si})}= & {\left[\psi_{(\mathrm{CdTe}, \mathrm{a}-\mathrm{Si})-\mathrm{cc}} \times \text { weight }_{\mathrm{cc}}\right] } \\
& +\left[\psi_{(\mathrm{CdTe}, \mathrm{a}-\mathrm{Si})-\mathrm{md}} \times \text { weight }_{\mathrm{md}}\right] \\
& +\left[\psi_{(\mathrm{CdTe}, \mathrm{a}-\mathrm{Si})-\mathrm{me}} \times \text { weight }_{\mathrm{me}}\right]
\end{aligned}
$$

where $\psi$ is the positive flow in a specific impact category (e.g., climate change) and weight $\mathrm{co}_{\mathrm{cc}}$ weight $_{\mathrm{md}}$, and weight $\mathrm{me}_{\mathrm{e}}$ represent the weights in the climate change, metal depletion and marine eutrophication, respectively. $\psi$ for climate change is calculated using eq 4 and the same is applicable for calculating the positive flows for metal depletion and marine eutrophication.

$$
\psi_{(\mathrm{CdTe}, \mathrm{a}-\mathrm{Si})-\mathrm{cc}}=\operatorname{PF}\left\{\mathrm{CdTe}_{\mathrm{cc}}-\mathrm{a}-\mathrm{Si}_{\mathrm{cc}}\right\}
$$

$\mathrm{CdTe}_{\mathrm{CC}}$ and $\mathrm{a}-\mathrm{Si}_{\mathrm{CC}}$ represent the climate change scores of CdTe and a-Si (stochastically sampled from Table 1) and PF represents a preference function (Figure 1).

The negative flow is similarly calculated by

$$
\psi_{(\mathrm{a}-\mathrm{Si}, \mathrm{CdTe})-\mathrm{cc}}=\operatorname{PF}\left\{\mathrm{a}-\mathrm{Si}_{\mathrm{cc}}-\mathrm{CdTe}_{\mathrm{cc}}\right\}
$$

The PF converts the relative difference in a specific environmental impact category (e.g., climate change) to an outranking score between 0 and 1 . Figure 1 shows the PF for $\mathrm{CdTe}$ and a-Si in the climate change impact category and the same applies to other pairwise comparisons between the PV technologies across the three environmental impact categories

$\mathrm{CdTe}_{\mathrm{CC}}$ and $\mathrm{a}-\mathrm{Si}_{\mathrm{CC}}$ are obtained through a Monte Carlo sampling from the mean and standard deviations in Table 1. The preference threshold $(\mathrm{p})$ represents the smallest difference in the environmental score in a particular impact category at which one PV technology is preferred over the other. ${ }^{47}$ If the difference between $\mathrm{CdTe}_{\mathrm{CC}}$ and $\mathrm{a}-\mathrm{Si}_{\mathrm{CC}}$ is less than $\mathrm{p}$, then $\mathrm{CdTe}$ has a lower climate change burden and is assigned a score $1\left(\mathrm{CdTe}_{\mathrm{CC}}=1\right)$. The indifference threshold (q) represents the largest difference in the environmental scores in a particular impact category at which a PV technology is not preferred over the other. If the difference in the environmental impacts is greater than $\mathrm{q}$, then $\mathrm{CdTe}$ has a greater climate change burden and is assigned a score $0\left(\mathrm{CdTe}_{\mathrm{CC}}=0\right)$. If the difference in the environmental impacts lies between $q$ and $p$ then $\mathrm{CdTe}$ has a lower climate change burden and is assigned a 
value between 0 and 1 based on the expression shown in Figure 1. To calculate negative flows, climate change score of CdTe is subtracted from a-Si and the difference is similarly converted into an outranking score.

The values of $p$ and $q$ can be determined from the uncertainty in the characterization data ${ }^{27}$ or elicited from experts. ${ }^{48}$ We use the former approach ${ }^{27}$ and calculate $\mathrm{p}$ and $\mathrm{q}$ (e.g., for climate change) as

$$
\begin{aligned}
& p=\left(\mathrm{SD}_{\mathrm{cc} \__{-} \mathrm{CdTe}}+\mathrm{SD}_{\mathrm{cc} \_\mathrm{a}-\mathrm{Si}_{\mathrm{i}}}\right) \div 2 \\
& \mathrm{q}=\mathrm{p} \div 2
\end{aligned}
$$

where, $\mathrm{SD}_{\text {cc_CdTe }}$ and $\mathrm{SD}_{\text {cc_a-Si }}$ is the standard deviation for climate change for $\mathrm{CdTe}^{-}$and a-Si (Table 1). A similar calculation is used to calculate $\mathrm{p}$ and $\mathrm{q}$ for marine eutrophication and metal depletion.

It is important to note that the relative environmental score (rel_score) is similarly calculated for a-Si and Ribbon-Si using eqs $\overline{2}-7$.

The calculation of the relative environmental score for the three PV technologies (rel_score) is then repeated for 10000 runs based on the environmental impact scores that are stochastically sampled from the log-normal distributions in Table 1. In each run, the PV alternatives are ranked first to third based on the relative environmental score. The first rank is assigned to the most environmentally preferable PV technology with a relative score closest to +1 . Similarly, the third rank is assigned to the least environmentally preferable PV technology with a relative score closest to -1 . Thus, the PV technology that is ranked first most often (out of a 10000 runs) is the most environmentally preferable alternative. The overlap in the likelihood of multiple PV technologies obtaining the first rank is a measure of the uncertainty in the choice of the environmentally preferred PV technology. For instance, if a$\mathrm{Si}, \mathrm{CdTe}$, and ribbon-Si obtain the first rank in 36, 34, and $30 \%$ of the 10000 runs there is a significant overlap and uncertainty in the choice of the environmentally preferred technology. However, if a-Si, CdTe, and ribbon-Si obtain the first rank in 75,20 and $5 \%$ of the 10000 runs then a-Si is clearly the environmentally preferred alternative.

Moment Independent Sensitivity Analysis for the Absolute Assessment. For the absolute assessment, the aggregate uncertainty in the weighted score of a PV technology (eq 1) is dependent on the uncertainty in each of the six parameters, the scores in the three environmental impact categories and the corresponding weights (Table 1). We use the moment independent sensitivity analysis method to calculate the delta $(\delta)$ indices for the six parameters that contribute to the uncertainty of the weighted score (weight score in eq 1). The uncertainties of the parameter with the highest $\delta$ index values contributes the most to the uncertainty in the weighted score (weighted_score, eq 1). The calculation of the $\delta$ indices is outlined in Figure 2 and for further details the reader can refer. ${ }^{30}$

Moment Independent Sensitivity Analysis for the Anticipatory Assessment. For the anticipatory assessment, the aggregate uncertainty in the relative environmental score of a PV technology (eq 2) is dependent on the uncertainty in each of the 12 parameters - the scores of the specific PV technology and the two competing alternatives in the three environmental impact categories (Table 1) and the weights for the three environmental impact categories-as the values of the normalization factors are fixed. ${ }^{42}$ The identification and ranking of the uncertainties is similar to the approach shown in Figure 2 with the following modifications: $\mathrm{IP}_{\mathrm{A}}, \mathrm{IP}_{\mathrm{B}}$, and $\mathrm{IP}_{\mathrm{c}}$ in steps 1,2 , and 4 have 12 columns corresponding to the 12 input parameters, the relative score (rel_score) is calculated in steps 3 and 5 using eq 2 , and $S_{\mathrm{j}}$ and $\delta_{\mathrm{j}}$ are calculated for each of the 12 parameters in step 7 and 8.

Simulating R\&D Outcomes from Addressing Critical Uncertainties in Absolute and Anticipatory Assessment. R\&D strategies can be specifically designed to address critical parameter uncertainties and, thereby, improve decisionconfidence in the choice of the environmentally preferred emerging technology. This study simulates and contrasts the outcomes of two R\&D scenarios that are informed by and address the critical uncertainties in the absolute and the anticipatory assessment. In each scenario, a hypothetical R\&D strategy is simulated by decreasing the mean of the critical parameter by one standard deviation and the standard deviation by $50 \%$. The reduction in the mean of the critical impact category score represents an increased environmental efficiency resulting from $\mathrm{R} \& \mathrm{D}$, while the decrease in standard deviation represents a reduction in uncertainty. The decrease in mean and standard deviation is assumed to be achieved through laboratory experiments that improve the performance and measurement accuracy of the energy or material inventory items that contribute significantly to the critical environmental impact score. The corresponding impact of the R\&D strategy is determined by recalculating the overlap in PV technologies obtaining the first rank based on the modified mean and the standard deviation (Figure 5). The R\&D strategy resulting in the least overlap will result in the greatest confidence in the comparative technology selection.

\section{RESULTS AND DISCUSSION}

Absolute and Anticipatory Assessment of the PV Technologies. In the absolute assessment (Figure 3, left), there is a significant uncertainty in the choice of the environmentally preferable PV technology, as there is an overlap in the range of the weighted scores of a-Si (mean $=1.99$ $\left.\times 10^{-06}, \mathrm{SD}=4.95 \times 10^{-07}\right)$, CdTe $\left(\right.$ mean $=1.87 \times 10^{-06}, \mathrm{SD}$ $\left.=4.32 \times 10^{-07}\right)$, and Ribbon-Si (mean $=1.96 \times 10^{-06}, \mathrm{SD}=$ $\left.3.84 \times 10^{-07}\right)$. We apply the Kruskal-Wallis $(\mathrm{KW})$ test $^{49}$ to demonstrate that the uncertainty in the choice of the environmentally preferable PV technology is significant. The $\mathrm{KW}$ test tests if the difference between the weighted scores of two PV technologies is statistically significant. The results show that the weighted scores for a-Si and CdTe, and a-Si and Ribbon-Si are statistically indistinguishable (SI Section 4).

In the anticipatory assessment, a-Si and $\mathrm{CdTe}$ are ranked first $45 \%$ and $50 \%$ in 10000 runs, respectively. Ribbon-Si obtains a third rank with a likelihood of $79 \%$ in 10000 runs as it has significantly higher score in the marine eutrophication and climate change impact categories, which are weighed higher than the metal depletion category (Table 1). However, in the absolute assessment, the environmental performance of ribbon$\mathrm{Si}$ is comparable with that of $\mathrm{a}-\mathrm{Si}$ and $\mathrm{CdTe}$ as there is a significant uncertainty in the weighted_score of the three PV technologies (Figure 3, left and SI Section 4). The uncertainty persists despite Ribbon-Si having a significantly higher impact in climate change and marine eutrophication categories than CdTe and a-Si (Table 1), and climate change and marine eutrophication being assigned higher weights in the decision. This can be attributed to the external normalization factors that are used only in the absolute assessment to calculate the 
weighted score and performance compensation across environmental impact categories. The weighted score of the three PV technologies is less sensitive to the performance in the marine eutrophication category, which is $3-4$ orders of magnitude lower than climate change and metal depletion (Table 1 and Figure 4). Furthermore, the weighted score of the three PV technologies is less sensitive to the performance in the climate change category as the normalization factor for climate change $\left(0.0000892 \mathrm{~kg} \mathrm{CO}_{2} \mathrm{eq}^{-1}\right)$ is $1-3$ orders of magnitude lower than metal depletion $\left(0.0014 \mathrm{~kg} \mathrm{Fe} \mathrm{eq}^{-1}\right)$ and marine eutrophication $\left(0.0988 \mathrm{~kg} \mathrm{~N}-\mathrm{e} q^{-1}\right)$. As a result, in the absolute assessment, the weighted scores of the three PV technologies is most sensitive to the performance in the metal depletion category. Therefore, the poor performance of Ribbon-Si in the climate change and marine eutrophication is compensated by the superior performance in the metal depletion category. The discrepancy in the relative environmental performance of Ribbon-Si in the absolute and the anticipatory assessment highlights the shortcoming of using external measures of normalization to inform comparative, decision-driven assessments. The external measure of normalization masks poor performance in specific impact categories (e.g., climate change and marine eutrophication) and can potentially misinform comparative, decision-driven assessments. For example, a decision-maker seeking to identify a PV alternative with a low climate change and marine eutrophication footprint can be misinformed to choose Ribbon-Si as the environmental performance of the Ribbon-Si is comparable with that of a-Si and CdTe (Figure 3, left). This is despite Ribbon-Si having a higher burden in the climate change and marine eutrophication categories.

Moment Independent Sensitivity Analysis. The results of the moment independent sensitivity analysis, identifying the significant uncertainties in the absolute and the anticipatory assessment, is depicted in Figure 4 for a-Si and section 1 of the SI for CdTe and Ribbon-Si. It is important to reiterate that the aggregate uncertainty is dependent on the uncertainty in each of the six parameters in the absolute assessment (Figure 4 left) and 12 paramaters in the anticipatory assessment (Figure 4 right). In the absolute assessment, the uncertainty in the weight and the impact category score for metal depletion contribute the most to the overall uncertainty in the absolute environmental score of the a-Si, CdTe and Ribbon-Si technologies (SI Figure 4 and section 1). However, in the anticipatory assessment, the uncertainty in the marine eutrophication score contributes the most (among 12 parameters) to the overall uncertainty of the relative environmental score (rel_score) of the a-Si, CdTe and Ribbon-Si technologies (SI Figure 4 and section 1). This is further emphasized by the marine eutrophication of the CdTe and ribbon-Si having a " $\delta$ " index value than the metal depletion and climate change scores of aSi.

Simulated R\&D Outcomes from Addressing Critical Uncertainties in Absolute and Anticipatory Assessment. Figure 5 contrasts the outcomes from pursuing R\&D strategies that address the critical uncertainties identified by the moment independent sensitivity analysis in the absolute and the anticipatory assessment. An R\&D strategy that reduces the uncertainty in the metal depletion score for a-Si, a critical uncertainty in the absolute assessment (Figure 4, left), produces the most improvement in the environmental performance of a-Si (SI Figure S11).
However, a reduction in the uncertainty of metal depletion does not improve decision-confidence in the choice between the a-Si and the CdTe as the environmentally preferred PV technology. a-Si and CdTe obtain the first rank with a likelihood of 51 and $45 \%$ in 10000 runs (Figure 5, center) and this overlap is similar to the baseline scenario where they are ranked first with a likelihood of 45 and 50\% (Figure 5, left), respectively.

In contrast, an R\&D strategy that decreases the uncertainty in the marine eutrophication score for a-Si, a critical uncertainty in the anticipatory assessment (Figure 4, right), improves decision confidence as a-Si is environmentally preferred over CdTe with a $76 \%$ likelihood in 10000 runs (Figure 5, right). This is significantly greater than the baseline scenario where aSi has a $45 \%$ likelihood of being the environmentally preferred alternative in 10000 runs (Figure 5, middle).

Similar results are observed for CdTe (SI Figure S5 and S8) and Ribbon-Si (SI Figures S12 and S13). Furthermore, SI Figures S3, S4, S6, S7, S9, and S10 show that the relative rankings are more sensitive to a reduction in the mean of the metal depletion and marine eutrophication scores than the standard deviation.

The findings also highlight the importance of resolving the uncertainty in the choice of the environmentally preferred emerging technology alternative before addressing the hotspot of a specific technology. Without resolving the uncertainty between $\mathrm{a}-\mathrm{Si}$ and $\mathrm{CdTe}$ as the environmentally preferred alternative, the decision maker can either invest in addressing the environmental hotpots of $\mathrm{CdTe}$ or a-Si, which is metal depletion. At best, investing in $\mathrm{R} \& \mathrm{D}$ to improve the metal depletion of a-Si will not resolve the uncertainty in the choice between $\mathrm{a}-\mathrm{Si}$ and $\mathrm{CdTe}$ as the environmentally preferred alternative (Figure 5). At worst, investing in $\mathrm{R} \& \mathrm{D}$ to improve the metal depletion of CdTe (a hotspot for CdTe, SI Figure S5) is counterproductive from an environmental standpoint. Despite improving the environmental performance of CdTe, this $R \& D$ investment is not contributing toward improving the most environmentally favorable option, which is a-Si.

The results in SI Figure 4 and section 1 call attention to the difference in the critical uncertainties in the absolute and the anticipatory evaluation of the emerging technologies. The absolute approach is primarily used to inform R\&D strategies for improving the environmental performance of individual emerging technologies, whereas the anticipatory approach directs $\mathrm{R} \& \mathrm{D}$ strategy toward decreasing the uncertainty in the choice between multiple alternatives. Uncertainty analysis in the absolute assessment is best suited to inform $\mathrm{R} \& \mathrm{D}$ decisions that produce the greatest improvements in the environmental performance of a single technology (SI Section $3)$. However, the uncertainty analysis in the absolute assessment can misdirect $\mathrm{R} \& \mathrm{D}$ effort toward addressing uncertainties that are not significant when the comparative decision is unclear and normalization and weighting have been applied to multiple impact criteria. For example, focusing experimental effort toward addressing the uncertainty in metal depletion impact category, which is the most critical uncertainty in the absolute assessment for CdTe (SI Figure S1 left), produces the greatest environmental improvement for CdTe (SI Figure S12). However, addressing the metal depletion uncertainty will not decrease the uncertainty in the choice between a-Si or CdTe (SI Figure S5 left) as metal depletion is not in the top three uncertainties that undermine decision confidence (SI Figure S1 right). Instead, having identified marine eutrophication (SI 
Figure S1 right), specific $R \& D$ efforts to reduce marine eutrophication uncertainties can include designing experiments to improve data quality in those parameters or probability distributions that contribute to uncertainty of marine eutrophication data sets.

The principal advantages of the anticipatory, decision-driven approach illustrated here are several:

- It allows analysis to proceed under conditions of high data uncertainty by relying on expert judgment of probability distributions, which can subsequently be tested for relevance to the decision when normalization and weighting is applied across multiple environmental impact categories. In some cases, such as ribbon-Si, technologies may be eliminated from further consideration without additional analysis in a given decision context.

- It allows testing research hypotheses (represented as a change in the probability assignment of material or energy inventory data) that explore the level of technology improvement necessary to reverse an environmental preference rank ordering.

- It facilitates conservation of research resources by focusing efforts on those uncertainties that are most relevant to the decision as opposed to the improvement of a single technology.

Current LCA software provide features for magnitude based contribution analysis which identifies the material and energy inventory items that contribute the most toward the characterized environmental impact scores. Furthermore, the features for uncertainty assessment in LCA software quantify the overall uncertainty in the characterized environmental impact scores. However, neither the contribution analysis nor the uncertainty assessment in existing LCA packages can identify the key uncertainties in the material and energy inventory items that contribute the most to the uncertainty in the characterized environmental impact scores. As a result, the uncertainty assessment in Figure 4 is terminated at the level of environmental impact categories as standard commercial LCA software have limited features to explore uncertainty disaggregation at the material and energy flow level. The authors reemphasize that this is a limitation of commercial software typically used by practitioners to conduct LCAs and not a limitation of the proposed novel sensitivity-analysis method. This calls for future research toward uncertainty assessment of the underlying inventory items in proprietary and open source LCA software ${ }^{50}$ to inform decisions on prioritizing R\&D effort toward reducing uncertainty in key energy and material data sets of emerging technologies.

For simplicity and illustrative purposes, this research considers only three impact categories, three technology alternatives and addresses only parameter uncertainties. The case study of PV technology, the three impact categories, and the upper and lower limits of the uniform distribution for the weights are chosen to best illustrate the utility of the novel sensitivity analysis approach. The anticipatory framework can be applied to other emerging technologies beyond PV without any modifications to the methods presented in this work. In addition, the anticipatory framework can be extended to include other impact categories, different upper and lower limits for the uniform distribution and different distribution types for the weights, greater number of technology alternatives (minimum requirement is two alternatives), model and scenario uncertainty, ${ }^{51}$ and uncertainty in normalization factors. For example, based on the lifecycle inventory data for emerging technology alternatives which are under investigation, the distributions for multiple impact categories (e.g., ozone depletion potential, fossil depletion potential in $\mathrm{ReCiPe}$ ) can be determined in SimaPro and included though a Monte Carlo sampling in eq 2 . The moment independent sensitivity analysis can then include the additional impact categories to inform $\mathrm{R} \& \mathrm{D}$ and improve decisions on the choice between the emerging technologies under investigation. It should be noted computational time for calculating the moment independent sensitivity analysis index $(\delta)$ increases with an increasing number of emerging technology alternatives and the impact categories.

\section{ASSOCIATED CONTENT}

\section{Supporting Information}

The Supporting Information is available free of charge on the ACS Publications website at DOI: 10.1021/acs.est.7b04517.

Results identifying critical uncertainties for CdTe and ribbon-Si in the absolute and the anticipatory assessment, the relative environmental rankings when $\mathrm{R} \& \mathrm{D}$ decreases the critical uncertainties identified in the absolute and the anticipatory assessment for $\mathrm{CdTe}$ and ribbon-Si and the results of the Kruskal-Wallis test (PDF)

\section{AUTHOR INFORMATION}

\section{Corresponding Author}

*E-mail: dtriplic@asu.edu.

ORCID

Dwarakanath Ravikumar: 0000-0002-4824-1829

Thomas P. Seager: 0000-0001-7354-252X

Christopher Mutel: 0000-0002-7898-9862

\section{Notes}

The authors declare no competing financial interest.

\section{ACKNOWLEDGMENTS}

This study is primarily supported by the National Science Foundation (NSF) and the Department of Energy (DOE) under NSF CA No.EEC-1041895 and 1140190, the U.S. Environmental Protection Agency (EPA) under Assistance Agreement No. RD83558001, and the USAID under Cooperative Agreement Number AID-391-A-15-00001. Any opinions, findings and conclusions or recommendations expressed in this material are those of the author and do not necessarily reflect those of NSF, DOE, EPA or USAID. We also thank Lise Laurin from EarthShift Global and the anonymous reviewers for the feedback that has improved the quality of this paper.

\section{REFERENCES}

(1) Rebitzer, G.; Ekvall, T.; Frischknecht, R.; Hunkeler, D.; Norris, G.; Rydberg, T.; Schmidt, W. P.; Suh, S.; Weidema, B. P.; Pennington, D. W. Life cycle assessment Part 1: Framework, goal and scope definition, inventory analysis, and applications. Environ. Int. 2004, 30, $701-720$.

(2) Seager, T. P.; Theis, T. L. A uniform definition and quantitative basis for industrial ecology. J. Cleaner Prod. 2002, 10 (3), 225-235.

(3) Frosch, R. A.; Gallopoulos, N. E. Strategies for Manufacturing. Sci. Am. 1989, 261 (3), 144-152.

(4) Wender, B. A.; Foley, R. W.; Prado-Lopez, V.; Ravikumar, D.; Eisenberg, D. A.; Hottle, T. A.; Sadowski, J.; Flanagan, W. P.; Fisher, 
A.; Laurin, L.; et al. Illustrating anticipatory life cycle assessment for emerging photovoltaic technologies. Environ. Sci. Technol. 2014, 48 (18), 10531-10538.

(5) Seager, T. P.; Linkov, I. Uncertainty in Life Cycle Assessment of Nanomaterials. In Nanomaterials: Risks and Benefits; Linkov, I., Steevens, J., Eds.; Springer: Dordrecht, 2009; pp 423-436.

(6) Hertwich, E. G.; Hammitt, J. K. A decision-analytic framework for impact assessment part I: LCA and decision analysis. Int. J. Life Cycle Assess. 2001, 6 (1LB-ref1), 5-12.

(7) Hetherington, A. C.; Borrion, A. L.; Griffiths, O. G.; McManus, M. C. Use of LCA as a development tool within early research: Challenges and issues across different sectors. Int. J. Life Cycle Assess. 2014, 19 (1), 130-143.

(8) Lloyd, S. M.; Ries, R. Characterizing, propagating, and analyzing uncertainty in life-cycle assessment. J. Ind. Ecol. 2007, 11 (1), 161181.

(9) Frey, H. C.; Patil, S. R. Identification and review of sensitivity analysis methods. Risk Anal. 2002, 22, 553-578.

(10) Borgonovo, E.; Plischke, E. Sensitivity analysis: A review of recent advances. Eur. J. Oper. Res. 2016, 248 (3), 869-887.

(11) Cellura, M.; Longo, S.; Mistretta, M. Sensitivity analysis to quantify uncertainty in Life Cycle Assessment: The case study of an Italian tile. Renewable Sustainable Energy Rev. 2011, 15 (9), 46974705.

(12) Lacirignola, M.; Blanc, P.; Girard, R.; Pérez-López, P.; Blanc, I. LCA of emerging technologies: addressing high uncertainty on inputs' variability when performing global sensitivity analysis. Sci. Total Environ. 2016, 578, 268-280.

(13) Groen, E. A.; Bokkers, E. A. M.; Heijungs, R.; de Boer, I. J. M. Methods for global sensitivity analysis in life cycle assessment. Int. J. Life Cycle Assess. 2017, 22 (7), 1125-1137.

(14) Cucurachi, S.; Borgonovo, E.; Heijungs, R. A Protocol for the Global Sensitivity Analysis of Impact Assessment Models in Life Cycle Assessment. Risk Anal. 2016, 36 (2), 357-377.

(15) Wei, W.; Larrey-Lassalle, P.; Faure, T.; Dumoulin, N.; Roux, P.; Mathias, J. D. How to conduct a proper sensitivity analysis in life cycle assessment: Taking into account correlations within LCI data and interactions within the LCA calculation model. Environ. Sci. Technol. 2015, 49 (1), 377-385.

(16) Ravikumar, D.; Seager, T. P.; Chester, M. V.; Fraser, M. P. Intertemporal Cumulative Radiative Forcing Effects of Photovoltaic Deployments. Environ. Sci. Technol. 2014, 48 (17), 10010-10018.

(17) Ravikumar, D.; Sinha, P.; Seager, T. P.; Fraser, M. P. An anticipatory approach to quantify energetics of recycling CdTe photovoltaic systems. Prog. Photovoltaics 2016, 24 (5), 735-746.

(18) Prado-lopez, V.; Wender, B. A.; Seager, T. P.; Laurin, L.; Chester, M.; Arslan, E. Tradeoff Evaluation Improves comparative life cycle assessment: A Photovoltaic Case Study. J. Ind. Ecol. 2016, 20 (4), $710-718$.

(19) Rogers, K.; Seager, T. P. Environmental decision-making using life cycle impact assessment and stochastic multiattribute decision analysis: a case study on alternative transportation fuels. Environ. Sci. Technol. 2009, 43 (6), 1718-1723.

(20) National Research Council of the National Academies. Science and Decisions: Advancing Risk Assessment; National Academies Press, 2009.

(21) National Science and Technology Council Committee on Technology. National Nanotechnology Initiative. Environmental, Health, and Safety Research Strategy 2011, 65.

(22) Stern, P. C.; Fineberg, H. V. Understanding Risk: Informing Decisions in a Democratic Society, 1996.

(23) Norris, G. The requirement for congruence in normalization. Int. J. Life Cycle Assess. 2001, 6 (2), 85-88.

(24) Sleeswiik, A. W.; van Oers, L. F. C. M.; Guinée, J. B.; Struijs, J.; Huijbregts, M. A. J. Normalisation in product life cycle assessment: An LCA of the global and European economic systems in the year 2000. Sci. Total Environ. 2008, 390 (1), 227-240.
(25) Prado, V.; Wender, B.; Seager, T. P. Interpretation of comparative LCAs: External normalization and a method of mutual differences. Int. J. Life Cycle Assess. 2017, 22 (12), 2018-2029.

(26) Cucurachi, S.; Seager, T. P.; Prado, V. Normalization in Comparative Life Cycle Assessment to Support Environmental Decision Making. J. Ind. Ecol. 2017, 21 (2), 242-243.

(27) Prado-Lopez, V.; Seager, T. P.; Chester, M.; Laurin, L.; Bernardo, M.; Tylock, S. Stochastic multi-attribute analysis (SMAA) as an interpretation method for comparative life-cycle assessment (LCA). Int. J. Life Cycle Assess. 2014, 19 (2), 405-416.

(28) Borgonovo, E.; Tarantola, S. Moment Independent and Variance-Based Sensitivity Analysis with Correlations: An Application to the Stability of a Chemical Reactor. Int. J. Chem. Kinet. 2008, 40 (11), 687-698.

(29) Borgonovo, E.; Castaings, W.; Tarantola, S. Model emulation and moment-independent sensitivity analysis: An application to environmental modelling. Environ. Model. Softw. 2012, 34, 105-115.

(30) Wei, P.; Lu, Z.; Yuan, X. Monte Carlo simulation for momentindependent sensitivity analysis. Reliab. Eng. Syst. Saf. 2013, 110, 6067.

(31) Ravikumar, D.; Wender, B.; Seager, T. P.; Fraser, M. P.; Tao, M. A climate rationale for research and development on photovoltaics manufacture. Appl. Energy 2017, 189, 245-256.

(32) Green, M. Learning experience for thin-film solar modules: First Solar, Inc. case study. Prog. Photovoltaics 2011, 19 (4), 498-500.

(33) Nemet, G. F. Beyond the learning curve: factors influencing cost reductions in photovoltaics. Energy Policy 2006, 34 (17), 3218-3232.

(34) Fraunhofer Institute for Solar Energy Systems ISE. Photovoltaics Report http://www.ise.fraunhofer.de/en/downloads-englisch/ pdf-files-englisch/photovoltaics-report-slides.pdf (accessed February 1, 2017).

(35) Hsu, D. D.; O’Donoughue, P.; Fthenakis, V.; Heath, G. A.; Kim, H. C.; Sawyer, P.; Choi, J. K.; Turney, D. E. Life Cycle Greenhouse Gas Emissions of Crystalline Silicon Photovoltaic Electricity Generation: Systematic Review and Harmonization. J. Ind. Ecol. 2012, 16 (S1), S122-S135.

(36) Kim, H. C.; Fthenakis, V.; Choi, J. K.; Turney, D. E. Life Cycle Greenhouse Gas Emissions of Thin-film Photovoltaic Electricity Generation: Systematic Review and Harmonization. J. Ind. Ecol. 2012, 16 (S1), S110-S121.

(37) Ravikumar, D. An Anticipatory-Lifecycle Approach Towards Increasing the Environmental Gains from Photovoltaic Systems Through Improved Manufacturing and Recycling, $\mathrm{PhD}$ Thesis, Arizona State University, Tempe, AZ, 2005, 2016.

(38) Hernandez, R. R.; Hoffacker, M. K.; Murphy-Mariscal, M. L.; Wu, G. C.; Allen, M. F. Solar energy development impacts on land cover change and protected areas. Proc. Natl. Acad. Sci. U. S. A. 2015, 112 (44), 13579-13584.

(39) Candelise, C.; Winskel, M.; Gross, R. Implications for CdTe and CIGS technologies production costs of indium and tellurium scarcity. Prog. Photovoltaics 2012, 20 (6), 816-831.

(40) Fthenakis, V. Sustainability metrics for extending thin-film photovoltaics to terawatt levels. MRS Bull. 2012, 37 (4), 425-430.

(41) Ravikumar, D.; Malghan, D. Material constraints for indigenous production of CdTe PV: Evidence from a Monte Carlo experiment using India's National Solar Mission Benchmarks. Renewable Sustainable Energy Rev. 2013, 25, 393-403.

(42) Goedkoop, M.; Heijungs, R.; Huijbregts, M.; Schryver, A.; De Struijs, J.; van Zelm, R. ReCiPe 2008 - A Life Cycle Impact Assessment Method Which Comprises Harmonised Category Indicators at the Midpoint and the Endpoint Level, 2009.

(43) Finnveden, G.; Hofstetter, P.; Bare, J.; Basson, L.; Ciroth, A.; Mettier, T.; Seppälä, J.; Johansson, J.; Norris, G.; Volkwein, S. Normalization, grouping and weighting in life cycle impact assessment. In Life Cycle Impact Assessment: Striving Towards Best Practice; Society of Environmental Toxicology and Chemistry (SETAC), 2002.

(44) Johnsen, F. M.; Løkke, S. Review of criteria for evaluating LCA weighting methods. Int. J. Life Cycle Assess. 2013, 18 (4), 840-849. 
(45) Jolliet, O.; Margni, M.; Charles, R.; Humbert, S.; Payet, J.; Rebitzer, G.; Robenbaum, R. K. IMPACT 2002+: A New Life Cycle Impact Assessment Methodology. Int. J. Life Cycle Assess. 2003, 8 (6), 324-330.

(46) Brans, J.-P.; Mareschal, B. Promethee Methods. In Multiple Criteria Decision Analysis: State of the Art Surveys; Springer: New York, NY, 2005; pp 163-186.

(47) Prado, V.; Rogers, K.; Seager, T. P. Integration of MCDA Tools in Valuation of Comparative Life Cycle Assessment. Life Cycle Assessment Handbook: A Guide for Environmentally Sustainable Products 2012, 413-431.

(48) Linkov, I.; Satterstrom, F. K.; Yatsalo, B.; Tkachuk, A.; Kiker, G. A.; Kim, J.; Gardner, K. Comparative Assessment of Several Multi-Criteria Decision Analysis Tools for Management of Contaminated Sediments; Linkov, I., Kiker, G. A., Wenning, R. J., Eds.; Springer: Dordrecht, 2007.

(49) Kruskal, W. H.; Wallis, W. A. Use of Ranks in One-Criterion Variance Analysis. J. Am. Stat. Assoc. 1952, 47 (260), 583-621.

(50) Pauliuk, S.; Majeau-Bettez, G.; Mutel, C. L.; Steubing, B.; Stadler, K. Lifting Industrial Ecology Modeling to a New Level of Quality and Transparency: A Call for More Transparent Publications and a Collaborative Open Source Software Framework. J. Ind. Ecol. 2015, 19 (6), 937-949.

(51) Huijbregts, M. Application of uncertainty and variability in LCA. Int. J. Life Cycle Assess. 1998, 3 (5), 273-280. 